\title{
Meningkatkan Motivasi Belajar Siswa Melalui Pemanfaatan Media Audio Visual : Studi Eksperimen Dalam Pembelajaran Tari
}

\author{
Increasing Student Motivation Through the Use of Audio \\ Visual Media: Experimental Study in Dance Learning
}

\author{
Yoyoh Siti Mariyah, Agus Budiman, Heny Rohayani \& Winda Dewi Audina \\ Departemen Pendidikan Tari, Fakultas Seni dan Desain, Universitas Pendidikan Indonesia \\ *Corresponding e-mail: agusbudiman@upi.edu
}

Diterima: 08 Juni 2021; Direview: 01 Agustus 2021; Disetujui: 14 Agustus 2021

\begin{abstract}
Abstrak
Penelitian ini memiliki tujuan dalam melihat adanya pengaruh media audio visual dalam pembelajaran tari untuk meningkatkan motivasi belajar siswa kelas VII-A di SMPN 1 Mangunjaya. Metode penelitian yang digunakan adalah metode pre eksperimen dengan desain The One Group Pretest-Posttest. Teknik pengumpulan data menggunakan teknik observasi, studi literatur, wawancara dan studi dokumentasi. Hasil penelitian menunjukan tidak adanya pengaruh siginifikan media audio visual dalam meningkatkan motivasi siswa kelas VII-A di SMPN 1 Mangunjaya, dilihat dari hasil analisis menunjukan nilai t didapatkan hasil sebesar $0.015>0.05$ dan nilai $t$ hitung $2.600<\mathrm{t}$ table 2,042, hasil analisis ini menunjukan bahwa pembelajaran tari dengan penerapan media audio visual tidak berpengaruh dalam meningkatkan motivasi belajar siswa, sehingga keputusan hipotesis adalah dapat disimpulkan bahwa H1 tidak terdapat pengaruh signifikan dari variabel X1 terhadap Y. Menerima H1 atau yang berarti tidak terdapat perbedaan bermakna antara nilai pretest dan posttest. Kesimpulannya bahwa media audio visual yang diterapkan dalam pembelajaran tari tidak terdapat pengaruh signifikan terhadap peningkatan motivasi siswa kelas VII-A di SMPN 1 Mangunjaya.
\end{abstract}

Kata Kunci: Audio Visual; Pembelajaran Tari; Motivasi Belajar

\begin{abstract}
This study aims to see the influence of audio-visual media in dance learning to increase the learning motivation of class VII-A students at SMPN 1 Mangunjaya. The research method used is the pre-experimental method with the design of The One Group Pretest-Posttest. Data collection techniques using observation techniques, literature studies, interviews and documentation studies. The results showed that there was no significant effect of audio-visual media in increasing the motivation of class VII-A students at SMPN 1 Mangunjaya, seen from the analysis results showed that the $t$ value was $0.015>0.05$ and the $t$ value was 2,600< $t$ table 2.042, the results of this analysis showed that dance learning with the application of audio-visual media has no effect in increasing student learning motivation, so the hypothesis decision is that it can be concluded that H1 does not have a significant effect on the variable X1 on Y. Accepting H1 or which means there is no significant difference between the pretest and posttest scores. The conclusion is that the audio-visual media applied in dance learning does not have a significant effect on increasing the motivation of class VII-A students at SMPN 1 Mangunjaya.
\end{abstract}

Keywords: Audio Visual; Dance Learning; Learning Motivation

How to Cite: Mariyah, S.Y., Budiman, A., Rohayani, H., \& Audina, D.W. (2021). Meningkatkan Motivasi Belajar Siswa Melalui Pemanfaatan Media Audio Visual: Studi Eksperimen Dalam Pembelajaran Tari. Journal of Education, Humaniora and Social Sciences (JEHSS), 4 (2): 959-967.

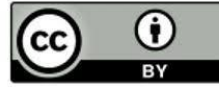




\section{PENDAHULUAN}

Media merupakan bagian yang melekat atau tidak terpisahkan dari proses pembelajaran untuk mencapai tujuan pembelajaran. Media berfungsi dan berperan mengatur hubungan efektif guru dan siswa dalam proses pembelajaran berlangsung (Fendrik, 2017; Putra, 2014). Proses pembelajaran merupakan suatu perpaduan yang tersusun rapi yang meliputi unsur-unsur manusiawi, material, fasilitas, perlengkapan dan prosedur yang saling mempengaruhi siswa untuk belajar. Kedudukan media pembelajaran sangat penting karena sebagai perantara dalam kegiatan pembelajaran untuk memberikan stimulus kepada siswa agar dapat memahami materi yang disampaikan oleh guru. Untuk memperjelas pesan yang disampaikan agar tidak terlalu verbal dan untuk mengatasi keterbatasan ruang, waktu, interaksi langsung antara siswa dengan sumber belajar dan untuk menimbulkan gairah belajar siswa. Media pembelajaran juga merupakan komponen sumber belajar yang mengandung materi instruksional dilingkungan siswa yang dapat memotivasi siswa untuk lebih giat belajar (Falahudin, 2014; Jailani \& Hamid, 2016; Muhson, 2010).

Pada hakekatnya bahwa pendidikan seni tari di lingkungan pendidikan formal memiliki kedudukan yang penting dalam membantu membentuk kecerdasan peserta didik baik kecerdasan intelektual, emosional, estetis, prilaku (afektif) dan kecerdasan motoric (Rosala \& Budiman, 2020). Indikasi tersebut, membuktikan bahwa peran dan tanggung jawab pelaksanaan pendidikan seni tari di lingkungan formal memiliki makna tertentu di dalam membentuk kepribadian seseorang ke arah yang lebih matang dalam segala hal (Anggraini \& Hasnawati, 2016; Rosala, 2017; Yulianti, 2013). Pembelajaran tari semestinya diarahkan dalam membentuk perkembangan individual secara menyeluruh yang terkait dengan potensi pisik, emosi, intelektual dan spiritual kita (Margaret, 1985).

Dalam beberapa penelitian sebelumnya, pemanfaatan media audio visual digunakan guru untuk membantu siswa dalam meningkatkan pembelajaran mandiri siswa. Selain, itu dalam penelitian ini diarahkan siswa agar mampu mengembangkan kemampuan kreatifnya melalui pemanfaatan media audio visual (Fodli, 2015). Keberadaan media audio visual memiliki peranan penting sebagai salah satu komponen pembelajaran yang digunakan oleh guru dalam pembelajaran tari (Anggi Irdiana Kusuma, 2019; Marlinda, 2016). Selain itu, keberadaan media pembelajaran audio visual dimanfaatkan oleh guru untuk meningkatkan hasil belajar siswa melalui kegiatan apresiasi salah satunya. Purnomo \& Nugraheni, n.d., (2019) meneliti tentang pengembangan modul berbasis digital untuk meningkatkan kompetensi guru. Pangestika \& Yanuartuti, n.d., (2020) meneliti tentang pembelajaran seni tari dengan menggunakan media youtube sebagai inovasi dalam pembelajaran tari. Namun, belum ada yang meneliti tentang pemanfaatan media audio visual dalam pembelajaran tari untuk meningkatkan motivasi belajar siswa di sekolah SMP.

Media dalam pembelajaran tari diharapkan memilik efektif dan efisien (Hartono, 2010). Artinya keberadaan media dalam pembelajaran tari akan mampu mewujudkan pembelajaran yang efketif dan menarik bagi siswa (Agustin, 2016; Hidayatullah, 2017; Mashita, 2016). Dengan kehadiran media dalam pembelajaran akan membantu guru dalam menyampaikan pembelajaran dan posisi siswa akan lebih mudah dalam menerima materi pembelajaran yang di sampaikan oleh guru (Mulyanti, Habsary, \& Mustika, 2018; Wahyuni, 2017). Dalam hal ini media dalam pembelajaran pembelajaran tari merupakan satu kesatuan integral yang keberadaannya tidak dapat dipisahkan dalam kegiatan belajar mengajarnya (Komalasari, Budiman, Masunah, \& Sunaryo, 2021; Ni Luh, 2011).

Penerapan model audio visual ini diharapkan agar siswa dapat meningkatkan efektivitas dan motivasi dalam proses pembelajaran seni tari khususnya dalam memberikan materi pembelajaran tari tradisional (Amriyeni, Syarif, \& Iriani, 2013). Keberadaan media pembelajaran audio visual dalam pembelajaran tari mampu memberikan pengaruh terhadap hasil belajar siswa di sekolah (Amriyeni et al., 2013).

Aspek motivasi dalam belajar dapat dipandang sebagai dorongan mental yang mampu menggerakkan dan mengarahkan perilaku manusia, termasuk dalam perilaku belajar siswa di sekolah (Hamdu \& Agustina, 2011; Kusuma \& Subkhan, 2015; Ramli, 2014). Motivasi sebagai salah satu aspek yang berpengaruh pada hasil belajar siswa (Aritonang, 2008; Ricardo \& Meilani, 2017; 色 $h t t p: / / m a h e s a i n s t i t u t e . w e b . i d / o j s 2 /$ index.php/jehss (1. mahesainstitut@gmail.com 960 
Umam, 2019). Selain itu, aspek motivasi bagi siswa lebih dimaknai sebagai salah satu faktor yang mampu mendorong siswa agar memiliki keinginan untuk belajar (Emda, 2018; Ricardo \& Meilani, 2017; Umam, 2019). Dalam pembelajaran tari pun aspek motivasi diperlukan oleh guru dan siswa agar kegiatan pembelajaran dapat berjalan efektif dan efisien, terutama dalam meningkatkan hasil belajar siswa (Aisyah, 2014; Hera, 2018; Wulandari, 2006).

Tujuan dari penelitian ini adalah ingin mengetahui adanya pengaruh media audio visual dalam meningkatkan motivasi belajar siswa dalam pembelajaran tari.

\section{METODE PENELITIAN}

Metode penelitian ini adalah pre-eksperimental design dengan desain one-group pretes posttest design. Kerangka penelitian kuantitatif dalam desain one group pretest-posttest design terdapat bentuk konstruksi berpikir penelitian yang dimulai dari hasil pretest (01) sebelum diberikannya perlakuan atau treatment $(\mathrm{X})$ yaitu dengan penerapan media audio visual, kemudian pada tahap akhir dilakukan posttest (O2) untuk mengetahui hasil belajar siswa.

Lokasi penelitian yang dipilih oleh peneliti adalah SMP Negeri 1 Mangunjaya yang berada di jalan Mangunjaya No.565, Kabupaten Pangandaran, Jawa Barat. Menurut peneliti lokasi ini dipilih karena kurangnya motivasi belajar siswa dan kurangnya model dan media pembelajaran yang di terapkan oleh guru mata pelajaran yang bersangkutan.

Partisipasi dalam penelitian ini terdiri dari 32 siswa yang semuanya terfokus pada siswa kelas VIIA. Selain siswa, partisipan penelitian lainnya adalah guru seni budaya dan kepala sekolah di SMP Negeri 1 Mangunjaya. Pemilihan subjek penelitian atau responden dalam penelitian ini dilakukan dengan teknik purposive sampling.

Pengumpulan data penelitian dilakukan dengan beberapa cara observasi, dan wawancara(Budiman, Nugraheni, \& Purnomo, 2020). Instumen yang digunakan dalam penelitian ini lebih mengoptimalkan instrument observasi untuk mengukur adanya peningkatan motivasi belajar pada diri siswa. Selain pedoman observasi, data penelitian diperoleh dari hasil wawancara dengan guru seni budaya yang mengajar di sekolah SMP Negeri 1 Mangunjaya untuk memperoleh data mengenai kondisi motivasi belajar siswa sebelum mengikuti kegiatan belajar tari melalui media audio visual.

Analisis data yang digunakan dalam penelitian melalui beberapa tahapan anlisis, mulai dari analisis uji instrument melalui uji validitas dan reabilitas, uji normalitas (Harahap, 2021), uji homogenitas, uji T, uji F, uji koefisien determinasi (Hogenes, Van Oers, Diekstra, \& Sklad, 2016; Karabulut \& Kesli Dollar, 2016; Yakut \& Aydın, 2017). Dalam teknik analisis menggunakan program statistik SPSS version 22.0 for Windows. Uji validitas menggunakan rumus Product Moment Pearson. Uji menggunakan rumus Alpha Cronbach (Budiman, Agus, Karyati, 2021). Dalam uji normalitas dan homogenitas menggunakan pendekatan rumus uji Shapiro Wilk, dan uji hipotesis. Hasil uji dapat divisualkan dalam bentuk table sebagai berikut.

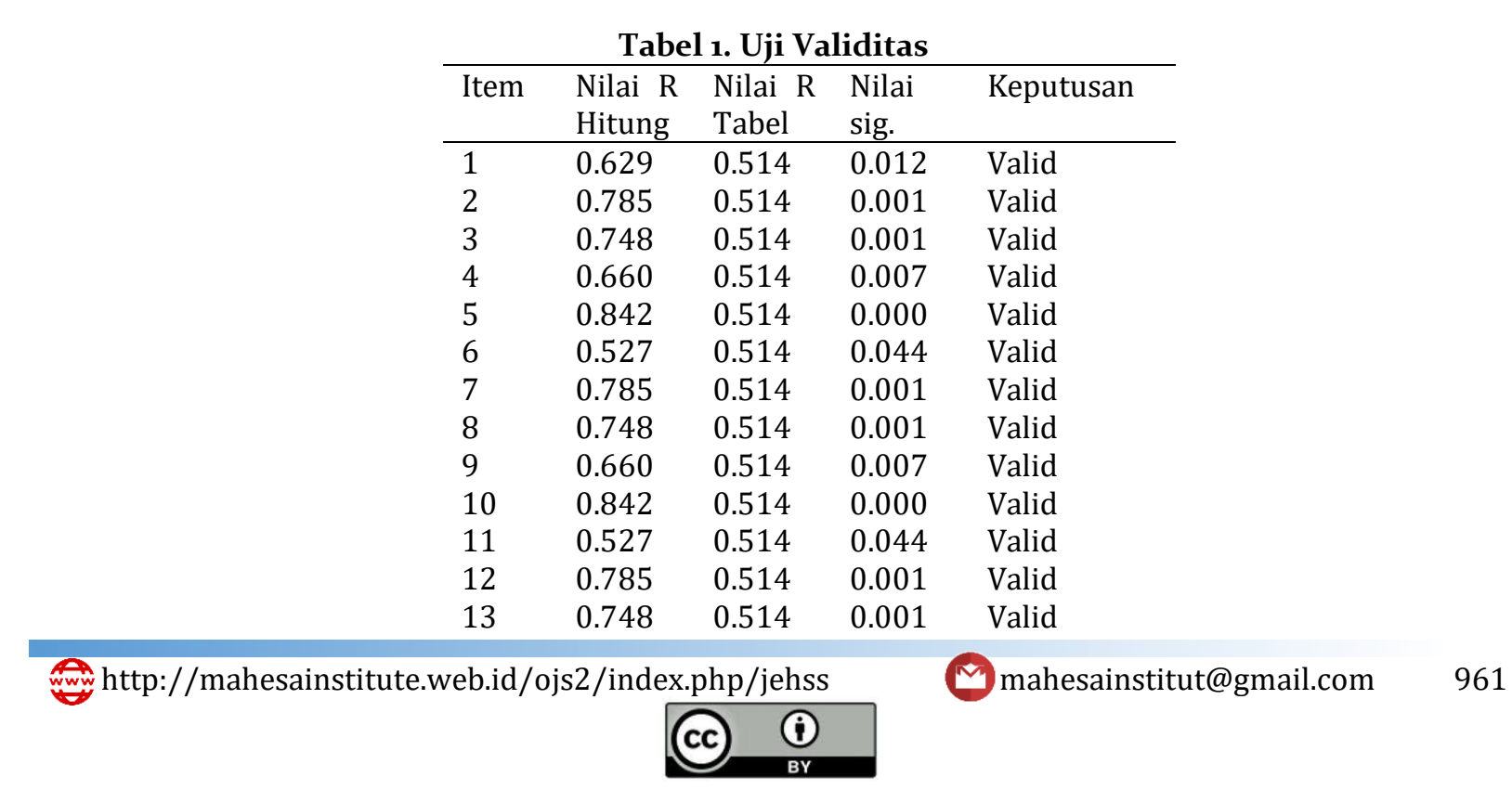


Yoyoh Siti Mariyah, Agus Budiman, Heny Rohayani \& Winda Dewi Audina, Meningkatkan Motivasi

14

0.660

0.514

0.007

Valid

Hasil perhitungan Uji Validitas sebagaimana table-tabel di atas, menunjukan bahwa semua harga rhitung > rtabel pada nilai signifikasi 5\%. Oleh karena itu, dapat disimpulkan bahwa semua item dalam angket penelitian ini Valid, sehingga digunakan sebagai instrument penelitian.

Tabel 2. Hasil Uji Reabilitas

\begin{tabular}{llll}
\hline Variabel & $\begin{array}{l}\text { Nilai } \\
\text { Hitung }\end{array}$ & $\begin{array}{l}\text { Nilai } \\
\text { Tabel }\end{array}$ & Keputusan \\
\hline Item & 0.847 & 0.514 & Reliabel \\
\hline
\end{tabular}

Dari output data SPSS di atas dapat dianalisis, hasil uji reabilitas dilakukan dengan menggunakan rumus alpha. Uji signifikasi dilakukan pada taraf a =0,05. Intrumen dapat dikatakan reliable jika nilai alpha lebih besar dari rtabel 0.514. Hasil hitung menunjukan bahwa $r$ hitung 0,847 > rtabel 0.514, maka kesimpulan hasil uji reabilitas ini menunjukan bahwa item instrument yang digunakan reliable atau menunjukkan konsistensi kelayakan.

\section{HASIL DAN PEMBAHASAN}

\section{Kondisi Motivasi Siswa Sebelum Diterapkan Audio Visual}

Peneliti menemukan proses pembelajaran yang berlangsung di SMPN 1 Mangunjaya dirasa kurang menarik dan membuat motivasi siswa untuk belajar menjadi kurang. Guru lebih banyak menggunakan metode ceramah tanpa menggunakan media pembelajaran apapun. Pembelajaran seni tari yang dilakukan pada kelas VII di SMPN 1 Mangunjaya ini mengacu kepada kurikulum 2013. Pada proses pelaksanaannya guru terlebih dahulu membuat Rencana Pelaksanaan Pembelajaran (RPP) yang akan dilaksanakan pada setiap pertemuan. Setelah itu guru melaksanakan pembelajaran yang mengacu pada RPP yang telah dibuat, lalu guru melakukan evaluasi pembelajaran sesuai dengan tujuan yang diterapkan oleh guru pada mata pelajaran seni budaya khusunya seni tari.

Berdasarkan hasil observasi yang dilakukan dengan cara wawancara kepada guru seni budaya kelas VII, proses pembelajaran seni tari di SMP Negeri 1 Mangunjaya masih terpaku kepada buku pembelajaran seni budaya yang ada. Materi seni budaya yang sering di ajarkan hanyalah seni musik dan seni rupa. Sedangkan meteri tentang seni tari hanya dua kali pertemuan saja, dan hanya sebatas pengetahuan umum tentang tari dan guru hanya memberikan tugas kepada siswa untuk merangkum materi yang ada pada buku pembelajaran. Bahkan siswa tidak diberi kesempatan untuk mengeksplore gerak secara langsung maupun melalui tayangan video, sehingga kreativitas siswa terbatas dan menyebabkan motivasi belajar siswa dalam mata pelajaran seni budaya khususnya seni tari kurang. Pembelajaran seni tari yang dilakukan oleh guru tersebut mungkin kurang terlaksana dengan baik, dikarenakan guru seni budaya kurang memahami pembelajaran seni tari karena guru tersebut lebih memahami mengenai materi pembelajaran seni rupa. Dan faktor lain yang menyebabkan kurangnya motivasi dalam proses pembelajaran seni tari karena guru masih menggunakan metode ceramah dan tanpa menggunakan alat bantu atau media apapun untuk menunjang kegiatan belajar mengajar di kelas.

Saat penelitian berlangsung, peneliti melihat para siswi yang cenderung diam, sedangkan siswa cenderung jahil dan membuat proses pembelajaran tidak kondusif. Pola komunikasi dikelas tidak berjalan secara efektif, hal ini terlihat disaat proses tanya jawab berlangsung para siswa tidak bisa memberikan respon sesuai yang diharapkan. Proses pemebalajaran diawali dengan motode ceramah dari guru tentang materi yang sesuai dengan silabus, dilanjutkan dengan siswa diminta untuk merangkum materi sesuai dengan bahan ajar.

Tabel 3. Distribusi Frekuensi Nilai Pretest Sebelum Diterapkannya Media Audio Visual Pada Pembelajaran Tari

↔ww $\mathrm{http}: / /$ mahesainstitute.web.id/ojs2/index.php/jehss

Nmahesainstitut@gmail.com 


\begin{tabular}{lllll}
\hline No. & Interval Kelas & frekuensi & Frekuensi kumulatif & Frekuensi relative \\
\hline 1 & 67 & 2 & 2 & $6,25 \%$ \\
2 & 68 & 7 & 9 & $21,87 \%$ \\
3 & 69 & 12 & 21 & $37,5 \%$ \\
4 & 70 & 8 & 29 & $25 \%$ \\
5 & 71 & 2 & 31 & $6,25 \%$ \\
6 & 72 & 1 & 32 & $3,12 \%$ \\
\hline
\end{tabular}

\section{Pengaruh Media Audio Visual Terhadap Motivasi Belajar Siswa Dalam Pembelajaran Tari Uji Normalitas}

Uji normalitas merupakan salah satu tahap analisis data yang digunakan sebagai syarat atau asumsi sebelum melakukan berbagai uji data dalam pendekatan statistic parametric. Tahapan ini merupakan tahapan wajib dilakukan untuk menguji data yang akan dianalisis berdistribusi normal atau tidak. Beberpa uji parametris yang melalui tahapan uji normalitas diantaranya uji regresi linear, Uji Ancova, Uji Independen T Test, Uji Manova, uji Anova, dan Uji Paired T Test . Analisis uji normalitas dalam penelitian ini dilakukan melalui program SPSS window 22. Adapun hasil analisis uji normalitas dalam data penelitian ini dapat dilihat dari data table output hasil analisis dari program SPSS sebagai berikut.

Table 4. Uji Normalitas

\begin{tabular}{lllllll}
\hline \multicolumn{6}{c}{ Kolmogorov-Smirnov $^{a}$} & \multicolumn{4}{l}{ Shapiro-Wilk } \\
\hline & Statistic & $d f$ & Sig. & Statistic & df & Sig. \\
\hline Kelas & .211 & 3 & .00 & .847 & 3 & .014 \\
Eksperi & & 2 & 1 & & 2 & \\
men & & & & & & \\
\hline
\end{tabular}

Ho : Data diambil dari populasi yang berdistribusi normal

H1 : Data diambil dari populasi yang tidak berdistribusi normal

Jika nilai Signifikansi > 0,05, maka data penelitian berdistribusi normal sehingga Ho diterima.

Jika nilai Signifikansi $<0,05$, maka data penelitian tidak berdistribusi normal sehingga Ho ditolak.

Berdasarkan hasil perhitungan dengan menggunakan SPSS, diperoleh hasil nilai singnifikansi nilai pottest $0,014>0,05$, maka H0 diterima sehingga dapat disimpulkan bahwa data diambil dari populasi penelitian berdistribusi normal. Sedangkan untuk nilai singnifikansi nilai posttest 0,014 >0,05, maka H0 diterima sehingga dapat disimpulkan bahwa data diambil dari populasi penelitian berdistribusi normal.

Uji homogenitas berbeda dengan uji normalitas meskipun sama-sama digunakan sebagai syarat dalam uji parametris. Uji homogenitas ini dilakukan untuk menguji data penelitian apakah memiliki sifat data yang homogen (sama) atau tidak homogeny (tidak sama). Perbedaan mendasar antara uji normalitas dengan uji homogenitas, jika uji normalitas diperlukan pada semua uji parametris, maka uji homogenitas tidak selalu digunakan. Uji homogenitas hanya digunakan pada uji parametris yang menguji perbedaan antara kedua kelompok data atau beberapa kelompok data yang dalam posisi sumber datanya memiliki perbedaan. Adapun hasil uji homogenitas dalam penelitian peneliti visualisasikan dalam data table output hasil uji homogenitas dari program SPSS window 22 yang digunakan dalam analisis data penelitian.

Table 5. Test of Homogeneity of Variances Motivasi Belajar

\begin{tabular}{cccc}
\hline Levene Statistic & $\mathrm{df}_{1}$ & $\mathrm{df}_{2}$ & Sig. \\
\hline .991 & 5 & 23 & .445 \\
\hline
\end{tabular}

1. Jika nilai Signifikansi $>0,05$, maka data penelitian miliki variansi sama sehingga Ho diterima. 
2. Jika nilai Signifikansi $<0,05$, maka data penelitian tidak memiliki variansi sama sehingga Ho ditolak.

Berdasarkan hasil perhitungan dengan menggunakan SPSS window 22 diperoleh hasil nilai singnifikansi 0,445 $<0,05$, maka H0 ditolak sehingga dapat disimpulkan bahwa data diambil dari populasi penelitian memiliki variansi sama atau tidak homogen. Untuk itu, data penelitian untuk pengujian hipotesis dapat dilakukan dengan teknik analisis statistic parametric.

Tabel 6. Uji T-Test

\begin{tabular}{llllll}
\hline \multicolumn{2}{l}{ Unstandardized Coefficients } & \multicolumn{2}{l}{ Standardized Coefficients } \\
Model & $\mathrm{B}$ & Std. Error & Beta & $\mathrm{t}$ & \multicolumn{1}{l}{ Sig. } \\
\hline 1 (Constant) & 53.206 & 8.485 & & 6.270 & .000 \\
\multicolumn{1}{l}{ Audio Visual } & .364 & .140 & .441 & 2.600 & .015 \\
a. Dependent Variable: Motivasi Belajar & & & \\
\hline
\end{tabular}

Diketahui nilai sig. untuk pengaruh X1 terhadap $\mathrm{Y}$ adalah sebesar $0.015>0.05$ dan nilai $\mathrm{t}$ hitung $2.600<\mathrm{t}$ table 2,042, sehingga dapat disimpulkan bahwa H1 tidak terdapat pengaruh signifikan dari variabel X1 terhadap Y.

\begin{tabular}{llllll}
\multicolumn{5}{c}{ Tabel 7. Uji F-Test } \\
ANOVA
\end{tabular}

a. Dependent Variable: Motivasi Belajar

b. Predictors: (Constant), Audio Visual

Berdasarkan output di atas diketahui nilai sig. untuk pengaruh $\mathrm{X}$ secara simultan terhadap $\mathrm{Y}$ adalah sebesar $0.015>0.05$ dan nilai $\mathrm{F}$ hitung $6.761>\mathrm{F}$ table 4,14, sehingga dapat disimpulkan bahwa $\mathrm{H} 1 / \mathrm{H} 2$ yang berarti ada terdapat pengaruh X terhadap Y.

Tabel 8. Uji Koefisien Diterminasi

Model Summary

\begin{tabular}{lllll}
\hline Model & R & \multicolumn{2}{c}{$\begin{array}{c}\text { Adjusted } \\
\text { R Square Square }\end{array}$} & $\begin{array}{c}\text { RStd. Error of } \\
\text { the Estimate }\end{array}$ \\
\hline 1 & $.441^{\mathrm{a}}$ & .195 & .166 & 5.15980 \\
\hline
\end{tabular}

a. Predictors: (Constant), Audio Visual

Berdasarkan output di atas diketahui nilai R sequare sebesar 0,195. Hal ini mengandung arti bahwa variable X1 dan X2 secara simultan terhadap variabel Y adalah sebesar 15,5\%.

Pembahasan hasil dari penelitian ini berisi pemaparan tentang motivasi belajar siswa dalam pembelajaran tari sebelum dan sesudah diterapkannya media audio visual yang dilaksanakan pada siswa kelas VII-A di SMP Negeri 1 Mangunjaya. Dalam penelitian ini, peneliti melakukan pretest dan memberikan perlakuan berupa penerapan media pembelajaran audio visual pada siswa kelas VII-A. Setelah dilakukannya penerapan media pembelajaran audio visual, peneliti melaksanakan posttest yang bertujuan untuk melihat hasil perlakuan yang telah diberikan dan melihat perubahan dari hasil penerapan media pembelajaran tersebut. Data yang diperoleh dari hasil tes tersebut merupakan data mentah, untuk mendapatkan kesimpulan dari data tersebut maka data harus diolah dan dianalisis secara statistik. Berdasarkan hasil setelah dilakukannya proses pembelajaran seni tari dengan penerapan media pembelajaran audio visual pada kelas VIIA dapat diketahui bahwa motivasi belajar siswa menjadi meningkat. Hal ini menunjukan bahwa 
kelas VII-A pada proses pembelajarannya berjalan dengan lancar dan dapat meningkatkan motivasi belajar siswa hingga dapat tercapai tujuan pembelajaran yang diinginkan. Dalam proses penelitian dilapangan sebelum peneliti melakukan penelitian, peneliti melihat motivasi belajar siswa dalam mata pelajaran seni budaya khususnya materi tari dinilai kurang. Karena siswa cenderung pasif dan pola komunikasi saat Tanya jawab mengenai materi dianggap kurang baik. Setelah peneliti menerapkan media pembelajaran audio visual, peneliti melihat adanya peningkatan motivasi belajar siswa. Perubahan tersebut dapat dilihat dari adanya peningkatan antusis siswa untuk mengikuti pembelajaran tari dengan semangat.

Pada saat proses penelitian, peneliti menerapkan media audio visual dilakukan sebanyak empat pertemuan. Pada pertemuan pertama dilakukan pretest, dilanjutkan dengan dua pertemuan dimana peneliti memberikan treatment atau penerapan media audio visual. Lalu pada pertemuan terakhir peneliti melakukan posttest untuk melihat hasil akhir pada penelitian ini. Hasil akhir yang akan menentukan seberapa besar atau ada tidaknya pengaruh penerapan media audio visual pada pembelajaran seni tari untuk meningkatkan motivasi belajar siswa. Pada tahap ini guru memberikan materi tayangan video untuk diapresiasi oleh siswa. Siswa diharapkan mampu untuk meniru dan mengeksplorasi gerak tarian. Pada saat diterapkannya media audio visual, siswa sudah mulai menunjukan adanya perubahan prilaku menjadi lebih bergairah pada saat pembelajaran berlangsung. Dalam proses pembelajaran setelah diterapkannya media audio visual, motivasi belajar siswa menjadi lebih meningkat dan siswa lebih aktif dan kreatif.

Berdasarkan hasil pengamatan terhadap siswa kelas VII-A yang dilakukan sebanyak empat pertemuan dengan satu pertemuan dilakukan pretest, dua pertemuan dilakukannya treatment dan satu pertemuan terakhir dilakukannya posttest terdapat nilai yang dihasilkan siswa sebelum dan sesudah di terapkannya treatment. Terdapat perkembangan yang signifikan antara hasil dan motivasi belajar siswa sebelum dan sesudah diterapkannya media audio visual dalam proses pemebelajaran seni tari dengan menggunakan uji-t. didapatkan bahwa hasil t hitung lebih besar dari t tabel, yaitu diketahui nilai sig. untuk pengaruh X1 terhadap Y adalah sebesar $0.015>0.05$ dan nilai t hitung $2.600<\mathrm{t}$ table 2,042, sehingga dapat disimpulkan bahwa H1 tidak terdapat pengaruh signifikan dari variabel X1 terhadap Y (tidak terdapat pengaruh yang signifikan dari penerapan media audio visual terhadap peningkatan motivasi belajar siswa kelas VII di SMP Negeri 1 Mangunjaya) ditolak, dan H1 (terdapat pengaruh yang signifikan dari penerapan media audio visual terhadap peningkatan motivasi belajar siswa kelas VII di SMP Negeri 1 Mangunjaya) diterima. Hal tersebut terbukti dengan adanya data nilai siswa dari hasil belajar yang diuji dengan uji-t didapatkan nilai t hitung lebih besara dari t tabel.

Adapun temuan yang peneliti temukan selama proses pembelajaran tari dengan penerapan media audio visual untuk meningkatkan motivasi belajar siswa kelas VII di SMP Negeri 1 Mangunjaya, yaitu ada beberapa hal yang harus diperhatikan oleh guru seni budaya yaitu guru dapat menggunakan media audio visual pada saat proses pembelajaran berlangsung untuk meningkatkan minat dan memotiasi siswa, dan guru juga dapat membimbing setiap keelompok yang mengalami kesulitan pada proses pembelajaran berlangsung.

\section{SIMPULAN}

Kondisi motivasi siswa dalam mengikuti pembelajaran tari sebelum diterapkan audio visual dalam pembelajaran tari di sekolah SMP Negeri 1 Mangunjaya kurang menunjukan motivasi tinggi. Hal ini dapat dilihat dari hasil pengematan proses pembelajaran sebelum penerapan media audio visual diberikan. Kecenderungan belajar siswa kurang banyak berpartisipasi dalam berbagai kegiatan belajar tari. Media audio visual yang diterapkan dalam pembelajaran seni tari, ternyata mampu menciptakan interaksi pembelajaran yang aktif, dinamis, dan menarik. Siswa tidak lagi dijadikan sebagai objek pendengar atau pengikut perintah guru, akan tetapi lebih menekankan bagaimana siswa mampu menganalisis, menginterpretasi, mengeksplorasi, menyelesaikan suatu persoalan sendiri dan memberi makna sendiri dari kegiatan pembelajaran yang telah dilakukan. Siswa lebih benyak berpartisipasi dalam kegiatan pembelajaran tari. Berdasarkan hasil penelitian dan pengolahan data dengan menggunakan uji t didapatkan hasil sebesar $0.015>0.05$ dan nilai $t$ hitung $2.600<t$ table 2,042, hasil analisis ini menunjukan bahwa pembelajaran tari dengan Wwit http://mahesainstitute.web.id/ojs2/index.php/jehss Nmahesainstitut@gmail.com 
penerapan media audio visual tidak memiliki pengaruh signifikan dalam meningkatkan motivasi belajar siswa.

\section{UCAPAN TERIMAKASIH}

Di akhir tulisan ini Kami ingin menyampaikan ucapan terimakasih kepada LPPM UPI yang telah memberikan ijin dan dana untuk melakukan kegiatan penelitian ini. Selain itu Kami ingin menyampaikan ucapan terima kasih juga kepada SMP Negeri 1 Mangunjaya yang telah mengijinkan Kami untuk melakukan penelitian ini.

\section{DAFTAR PUSTAKA}

Agustin, T. (2016). Pengembangan Video Pembelajaran Tari: Sebuah Alternatif Metode Belajar Tari. Imaji: Jurnal Seni Dan Pendidikan Seni, 14(1), 65-70.

Aisyah, P. (2014). Motivasi Siswa Dalam Pembelajaran Seni Tari Daerah Setempat SMA Adabiah Padang. Universitas Negeri Padang.

Amriyeni, M., Syarif, I., \& Iriani, Z. (2013). Pengaruh Audio Visual Terhadap Hasil Belajar Siswa dalam Pembelajaran Tari Daerah Setempat Kelas X SMA Negeri 8 Padang. Jurnal Sendratasik, 2(1), 56-62.

Anggi Irdiana Kusuma, N. (2019). Implementasi Media Audiovisual pada Pembelajaran Seni Budaya untuk Meningkatkan Rasa Percaya Diri Siswa di SMP Negeri 9 Yogyakarta. Institut Seni Indonesia Yogyakarta.

Anggraini, D., \& Hasnawati, H. (2016). Perkembangan Seni Tari: Pendidikan dan Masyarakat. Jurnal PGSD: Jurnal Ilmiah Pendidikan Guru Sekolah Dasar, 9(3), 287-293.

Aritonang, K. T. (2008). Minat dan motivasi dalam meningkatkan hasil belajar siswa. Jurnal Pendidikan Penabur, 7(10), 11-21.

Budiman, Agus, Karyati, D. (2021). Membentuk Karakter Kreatif: Bergerak Melalui Stimulus Permainan Tradisional. 11(2), 1-11.

Budiman, A., Nugraheni, T., \& Purnomo, P. (2020). The Effect of Architecture of Arts Education Tourism Towards Interest in Learning Arts for High School Students. Harmonia: Journal of Arts Research and Education, 20(2), 117-125.

Emda, A. (2018). Kedudukan motivasi belajar siswa dalam pembelajaran. Lantanida Journal, 5(2), 172-182.

Falahudin, I. (2014). Pemanfaatan Media dalam Pembelajaran. Lingkar Widyawiswara, 1(Desember), 104117.

Fendrik, M. (2017). The Effect of Media Visual in Three Dimensions Towards the Result of Math Learning at Elementary School. Pendas: Jurnal Ilmiah Pendidikan Dasar, 2(1), 1-14.

Fodli, A. (2015). Pembelajaran Tari Nusantara dengan Menggunakan Media Audio Visual Pada Siswa Kelas XI di SMA Negeri 1 Pangkah Kabupaten Tegal. Universitas Negeri Semarang.

Hamdu, G., \& Agustina, L. (2011). Pengaruh motivasi belajar siswa terhadap prestasi belajar IPA di sekolah dasar. Jurnal Penelitian Pendidikan, 12(1), 90-96.

Harahap, E. H. (2021). Pengaruh Pendekatan Contextual Teaching And Learning Berbantuan Media Tiga Dimensi Terhadap Motivasi Dan Hasil Belajar Matematika. Journal of Education, Humaniora and Social Sciences (JEHSS), 3(3), 829-835.

Hartono, H. (2010). Pemanfaatan Media Dalam Pembelajaran Tari Di Taman Kanak-kanak. Harmonia Journal of Arts Research and Education, 10(1), 62963.

Hera, T. (2018). Rangsang Audio Sebagai Motivasi Pada Penciptaan Karya Tari Tunggu Tubang Dalam Pembelajaran Koreografi Di Universitas Pgri Palembang. Jurnal Sitakara, 3(1), 58-68.

Hidayatullah, R. (2017). Media Audio Visual Dalam Pembelajaran Tari Melinting Di Mts Negeri 2 Bandar Lampung. Jurnal Seni Dan Pembelajaran.

Hogenes, M., Van Oers, B., Diekstra, R. F. W., \& Sklad, M. (2016). The effects of music composition as a classroom activity on engagement in music education and academic and music achievement: A quasiexperimental study. International Journal of Music Education, 34(1), 32-48. https://doi.org/10.1177/0255761415584296

Jailani, M. S., \& Hamid, A. (2016). Pengembangan sumber belajar berbasis karakter peserta didik (ikhtiar optimalisasi proses pembelajaran pendidikan agama islam (PAI)). Jurnal Pendidikan Islam, 10(2), 175-192.

Karabulut, A., \& Kesli Dollar, Y. (2016). The effects of presenting different types of vocabulary clusters on very young learners' foreign language learning. Education 3-13, 44(3), 255-268.

Komalasari, H., Budiman, A., Masunah, J., \& Sunaryo, A. (2021). Desain Multimedia Pembelajaran Tari Rakyat Berbasis Android Sebagai Self Directed Learning Mahasiswa Dalam Perkuliahan. Mudra Jurnal Seni Budaya, 36(1), 96-105.

赵 $h t t p: / /$ mahesainstitute.web.id/ojs2/index.php/jehss 
Kusuma, Z. L., \& Subkhan, S. (2015). Pengaruh Motivasi Belajar dan Kedisiplinan Belajar terhadap Prestasi Belajar Mata Pelajaran Akuntansi Siswa Kelas XI IPS SMA N 3 Pati Tahun Pelajaran 2013/2014. Economic Education Analysis Journal, 4(1).

Margaret, N. H. (1985). Doubler,. Dance A Creative Art Experience.

Marlinda, B. (2016). Pembelajaran Seni Tari dengan Menggunakan Media Audio Visual pada siswa Kelas VII D di SMP Negeri 1 Mlonggo. Universitas Negeri Semarang.

Mashita, M. (2016). Efektivitas Penggunaan Media Buku Saku dalam Pembelajaran Pendidikan Kewarganegaraan untuk Menumbuhkan Cinta Budaya Daerah Siswa (Studi Kuasi Eksperimen pada Siswa Kelas VII SMP Negeri 5 Malang). MODELING: Jurnal Program Studi PGMI, 3(1), 20-37.

Muhson, A. (2010). Pengembangan media pembelajaran berbasis teknologi informasi. Jurnal Pendidikan Akuntansi Indonesia, 8(2).

Mulyanti, D. S., Habsary, D., \& Mustika, I. W. (2018). Pembelajaran Tari Sigeh Penguten di RA Darul Falah Purworejo. Jurnal Seni Dan Pembelajaran, 6(4).

Ni Luh, S. (2011). Kontribusi Seni Tari Nusantara dalam Membangun Pendidikan Multikultur. MUDRA Jurnal Seni Budaya, 26(02), 126-134.

Pangestika, F. Y., \& Yanuartuti, S. (n.d.). Pembelajaran Mandiri Seni Tari Melalui Konten Youtube sebagai Inovasi Pembelajaran Masa Kini. Gondang: Jurnal Seni Dan Budaya, 4(2), 144-151.

Purnomo, E., \& Nugraheni, T. (n.d.). Pengembangan Modul Tari Berbasis Digital untuk Meningkatkan Kompetensi Guru Sekolah Menengah Tari. Gondang: Jurnal Seni Dan Budaya, 3(2), 119-127.

Putra, I. E. (2014). Teknologi media pembelajaran sejarah melalui pemanfaatan multimedia animasi interaktif. Jurnal TeknoIf, 1(2).

Ramli, R. (2014). The effect of learning motivation on student's productive competencies in vocational high school, West Sumatra. International Journal of Asian Social Science, 4(6), 722-732.

Ricardo, R., \& Meilani, R. I. (2017). Impak minat dan motivasi belajar terhadap hasil belajar siswa. Jurnal Pendidikan Manajemen Perkantoran (JPManper), 2(2), 188-201.

Rosala, D. (2017). Pembelajaran seni budaya berbasis kearifan lokal dalam upaya membangun pendidikan karakter siswa di sekolah dasar. Ritme, 2(1), 16-25.

Rosala, D., \& Budiman, A. (2020). Local Wisdom-based Dance Learning: Teaching Characters to Children through Movements. 7(3), 304-326. https://doi.org/10.17509/mimbar-sd.v7i3.28185

Umam, M. K. (2019). Penggunaan metode Jaritmatika dalam meningkatkan motivasi belajar. Awwaliyah: Jurnal Pendidikan Guru Madrasah Ibtidaiyah, 2(1), 45-68.

Wahyuni, B. T. (2017). Media Audio Visual dalam Pembelajaran Tari Melinting di MTs Negeri 2 Bandar Lampung.

Wulandari, H. (2006). Kajian tentang Motivasi Belajar Seni Tari melalui Kegiatan Apresiasi Seni pada Mahasiswa PGSD. Metodik Didaktik: Jurnal Pendidikan Ke-SD-An, 10(2).

Yakut, A. D., \& Aydın, S. (2017). An experimental study on the effects of the use of blogs on EFL reading comprehension. Innovation in Language Learning and Teaching, 11(1), 1-16. https://doi.org/10.1080/17501229.2015.1006634

Yulianti, D. (2013). Pembelajaran Seni Tari Berbasis Lingkungan Budaya: Studi Aplikatif Materi Penyadapan Seni Tradisi Daerah Setempat Oleh Siswa Kelas XI SMAN Rancakalong Kabupaten Sumedang. Universitas Pendidikan Indonesia. 